Sports Training

\title{
Women amateur street runners have a higher level of chronotype self- perception than men
}

\author{
Moisés Vieira de Carvalho ${ }^{1,2}$ (D), Juliana Bohnen Guimarães ${ }^{1}$ (D), \\ Camila Cristina Fonseca Bicalho $^{1}$ (D), Frederico Sander Mansur Machado ${ }^{2,3}$ (D), \\ Breno Barreto Lopes ${ }^{2}$ (D), Cândido Celso Coimbra ${ }^{2}$ (D) \\ ${ }^{1}$ Universidade do Estado de Minas Gerais, Departamento de Ciências do Movimento Humano, \\ Ibirité, MG, Brazil; ${ }^{2}$ Universidade Federal de Minas Gerais, Instituto de Ciências Biológicas, \\ Laboratório de Endocrinologia e Metabolismo, Belo Horizonte, MG, Brazil; ${ }^{3}$ Universidade \\ Estadual de Montes Claros, Departamento de Educação Física e Desportos, Centro de Ciências \\ Biológicas e da Saúde, Montes Claros, MG, Brazil.
}

Associate Editor: Gustavo R. da Mota, Universidade Federal do Triângulo Mineiro, Uberaba, MG, Brasil.

\begin{abstract}
Aim: The aims of the present study were to verify the self-perception level of the chronotype of amateur street runners and to test the association between the chronotype, gender, age, and preferred training time. Methods: A total of 166 amateur street runners were included $(q=89$, age $38.9 \pm 11.2$ years; $\delta=77$, age $38.0 \pm 9.7$ years). The Brazilian version of the Horne \& Östberg questionnaire was used to assess chronotypes and the preferred training time was determined through a multiple choice question. Based on chronotype definitions that suggest that when free to choose, morning-types (MT) would prefer training in the morning, evening-types (ET) in the evening and neither-types (NT) would not have a predilection for any specific time. The corroboration of this hypothesis was assumed as self-perception level of the chronotypes. Results: Women showed higher self-perception levels of their chronotype compared to men $\left(58.4 \% v s .41 .6 \% ; \chi^{2}=4.699 ; p=0.030\right)$. By chronotypes, MT, NT, and ET self-perception levels were $73.9 \%$, $15.9 \%, 88.9 \%$, respectively $\left(\chi^{2}=57.489 ; p<0.001\right)$. The most observed women circadian typology was MT, while in men it was NT $\left(\chi^{2}=8.951 ; p=0.011\right)$. However, there was no significant association between gender and preferred training time $\left(\chi^{2}=2.654 ; p=0.265\right)$. Age, female gender and preference to exercise during the day are associated with MT. Conclusion: Women runners showed a greater perception of their circadian traits than men, despite there was no association between gender and preferred training time.
\end{abstract}

Keywords: age, chronobiology phenomena, circadian rhythm, gender, running.

\section{Introduction}

Street races officially held in the Brazilian national territory are regulated by the Brazilian Athletics Confederation (CBAt), an entity affiliated with World Athletics, and following international rules ${ }^{1}$. Running involves men and women of various ages and physical fitness levels. In addition, the races take place at different times of the day, configuring a special point of interest for optimizing physical performance. These multiple factors provide a challenge for runners and coaches, especially from the perspective of the temporal organization of sports performance. In this sense, knowledge about inter-individual preferences for morning or evening hours which occurs as a reflection of circadian rhythmicity and external synchronizers, meaning the chronotype ${ }^{2}$, has become relevant for both the scientific and practitioners' context of sports training.
Chronotype is usually evaluated using self-assessment questionnaires such as the Morningness-Eveningness Personality Questionnaire (HÖ-MEQ) ${ }^{3}$, the Composite Scale of Morningness (CSM) ${ }^{4}$, and the Munich Chronotype Questionnaire (MCTQ) ${ }^{5}$. The chronotype can alternatively be determined from sleep parameters ${ }^{6}$. In the sports context, assessment of the circadian phenotype has covered runners of different levels ${ }^{7,8}$, professional rugby players $^{9}$, cyclists ${ }^{10}$, swimmers ${ }^{11}$, collegiate rowers ${ }^{12}$ and hockey and soccer players ${ }^{13,14}$.

The presence of endogenous rhythms would constitute an evolutionary acquisition reflecting a long consolidation process of an intrinsic timing system adapted to cyclical variations in fundamental elements of the environment, such as the presence/absence of light ${ }^{15}$. According to Minati et al. ${ }^{16}$ circadian types demonstrate the prevalence of sleep/wake time, and individuals classified 
as morning-types (MT) generally show greater activity and mood during the first hours of the clear phase, and those classified as evening-types (ET) show greater activity and mood during the first hours of the dark phase. Individuals classified as neither or intermediate-types (NT) tend to be more flexible, adjusting better to the schedules imposed by daily routines. Interestingly, although scoring the same result in the NT category, evidence suggests the existence of a circadian typology known as bimodal-types, which can be characterized by having two bouts of activity patterns with respect to the time of day ${ }^{17}$.

In addition, gender and age are factors which can alter the perception in self-knowledge of an individual's chronotype. Fischer et al. ${ }^{18}$ evaluated the chronotype distribution of 53,689 Americans over 12 years and observed that more than $50 \%$ of the chronotype changes throughout life occur during adolescence and early adulthood, and that this variation decreases with age. In a study with 14,650 volunteers on ontogenic modulation of the genderrelated chronotype, Duarte et al. ${ }^{19}$ reported that men apparently have greater plasticity in their circadian timing system throughout their lives. However, the same authors claim that the results of the literature regarding the interaction between gender, age and chronotype are few and contradictory at the time of the study.

Considering the hypothesis that age and gender might impact chronotype characterization with effects in sports performance, the aims of the present study were to verify the self-perception level of the chronotype of amateur street runners and to test the association between the chronotype, gender, age and preferred training time.

\section{Methods}

\section{Participants}

A total of 166 amateur street runners $(q=89$, age $38.9 \pm 11.2$ years; $\widehat{o}=77$, age $38.0 \pm 9.7$ years) mostly from the area of Belo Horizonte, MG, Brazil, volunteered to participate in this study. All volunteers included had participated in at least one street race over five kilometers in the previous 12 months and gave written informed consent in accordance with the Declaration of Helsinki. This protocol was approved by the Local Research Ethics Committee (number 4.033.818) and followed the rules established by the National Health Council in research involving humans.

\section{Experimental procedures}

This is a descriptive observational cross-sectional study carried out with amateur street runners between the months of July and August 2018. The running teams were cataloged and contacted via social media (Facebook, Whatsapp, and Email) to present the research objectives and procedures. After authorization from the coordinators, the Informed Consent Form containing the main information regarding the nature of the research was sent to the runners via Google Forms $\left(\mathrm{Google}^{\mathbb{C}}\right)$. If they digitally agreed, the volunteers were then directed to questions regarding the chronotype assessment and preferred training time using this same online tool. The questionnaires were anonymous, to maintain the privacy and confidentiality of all the information reported in the present research.

The chronotype was identified through the HÖ$\mathrm{MEQ}^{3}$ validated for the Brazilian population ${ }^{20}$. The HÖMEQ consists of 19 objective multiple choice questions. Each answer receives a value and the summation results in a final score ranging from 16 to 86 . The final score enables identifying the extreme morning-types (70-86), moderate morning-types (59-69), neither-types (42-58), moderate evening-types (31-41) and extreme evening-types (16-30) chronotypes.

The preferred training time was determined through a multiple choice question with the following answer options: morning, evening and no specific time. Based on chronotype definitions that suggest that when free to choose, MT would prefer training in the morning, ET in the evening and NT would not have a predilection for any specific time $\mathrm{e}^{21,22}$. Thus, the corroboration of this hypothesis was assumed as self-perception level of the chronotype.

\section{Statistical analysis}

Normality was tested using the Shapiro-Wilk test. Non-parametric data were analyzed by the Kruskal-Wallis ANOVA by ranks. The Pearson's chi-squared test $\left(\chi^{2}\right)$ was used to compare the frequency distribution of the chronotypes according to gender, and the preferred training time with gender. Logistic regression was used to assess the relationship between the chronotypes (dependent variable) and gender, age and preferred training time (independent variables). All statistical procedures were performed using SPSS 20.0 software package and the level of significance was set at $p<0.05$.

\section{Results}

Figure 1 shows the frequency distribution by the score obtained on the HÖ-MEQ following as presented by Cruz et al. ${ }^{8}$ The HÖ-MEQ score range in this study from 32 to 74 .

The circadian phenotypes were classified into three categories based on the HÖ-MEQ score. This classification model was adopted to meet the recommendation of grouping categories from the chi-squared test $\left(\chi^{2}\right)$ in case there is any answer less than 1 . Table 1 presents the proportion distribution results of the chronotype by gender. The most observed women circadian typology was MT, while in men it was NT $\left(\chi^{2}=8.951 ; p=0.011\right)$. However, 


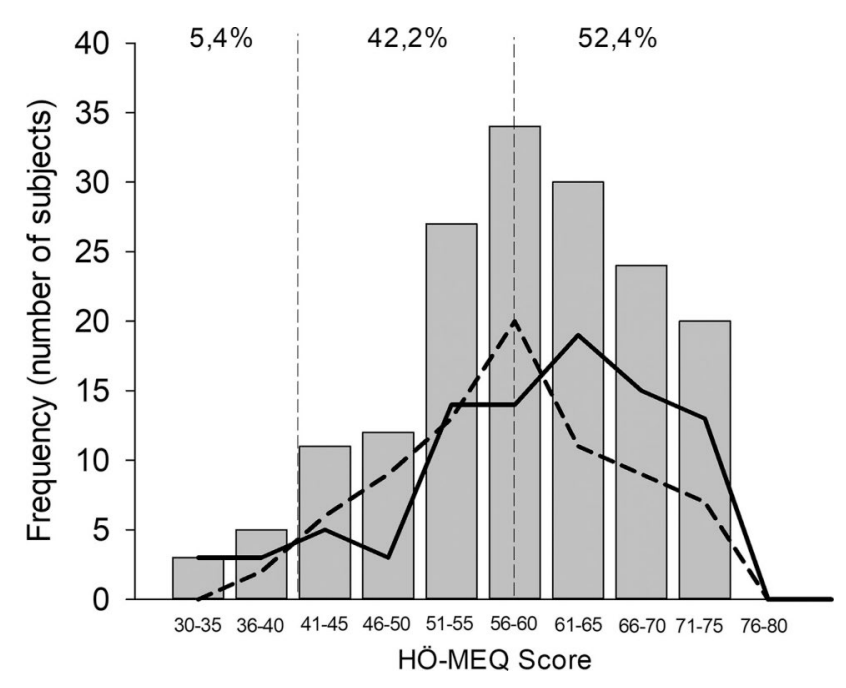

Figure 1 - Frequency distribution of the score obtained on the HÖ-MEQ. The dashed line indicates men, and the solid line indicates women. Classification: evening-types $(\leq 41)$, neither-types (42-58), morning-types $(\geq 59)$.

Table 1 - Absolute and relative distribution (\%) of the chronotypes by gender.

\begin{tabular}{ccccccc}
\hline Gender & MT & NT & ET & Total & $\chi^{2}$ & $p$ \\
\hline 0 & $34(44.2 \%)$ & $41(53.2 \%)$ & $2(2.6 \%)$ & $77(100 \%)$ & - & - \\
$\circ$ & $54(60.7 \%)$ & $28(31.4 \%)$ & $7(7.9 \%)$ & $89(100 \%)$ & - & - \\
Total & 88 & 69 & 9 & 166 & 8.951 & 0.011
\end{tabular}

Legend: ${ }^{\star}=$ men; $q$ = women. MT (morning-types), NT (neither-types), ET (evening-types).

there was no significant association between gender and preferred training time $\left(\chi^{2}=2.654 ; p=0.265\right)$ (Table 2).

Women showed higher self-perception levels of their chronotype compared to men $(58.4 \%$ vs. $41.6 \%$; $\chi^{2}=4.699 ; p=0.030 ;$ Figure $2 \mathrm{~A}$ ). By chronotypes, MT,
Table 2 - Absolute and relative distribution (\%) of preferred training hours by gender.

\begin{tabular}{|c|c|c|c|c|c|c|}
\hline Gender & Morning & Evening & $\begin{array}{c}\text { No specific } \\
\text { time }\end{array}$ & Total & $\chi^{2}$ & $p$ \\
\hline o & $\begin{array}{c}49 \\
(63.6 \%)\end{array}$ & $\begin{array}{c}17 \\
(22.1 \%)\end{array}$ & $\begin{array}{c}11 \\
(14.3 \%)\end{array}$ & $\begin{array}{c}77 \\
(100 \%)\end{array}$ & - & - \\
\hline 우 & $\begin{array}{c}55 \\
(61.8 \%)\end{array}$ & $\begin{array}{c}27 \\
(30.3 \%)\end{array}$ & $\begin{array}{c}7 \\
(7.9 \%)\end{array}$ & $\begin{array}{c}89 \\
(100 \%)\end{array}$ & - & - \\
\hline Total & 104 & 44 & 18 & 166 & 2.654 & 0.265 \\
\hline
\end{tabular}

Legend: $\sigma^{\star}=$ men; $\$=$ women.

NT, and ET self-perception levels were $73.9 \%, 15.9 \%$, $88.9 \%$, respectively $\left(\chi^{2}=57.489 ; p=0.000\right.$; Figure $\left.2 \mathrm{~B}\right)$. According to the standardized adjusted residual, MT and ET presented higher self-perception levels than expected. However, the NT showed the opposite pattern.

HÖ-MEQ data by gender and age range were arbitrarily allocated to four subgroups, being: $\leq 29,30-40,41$ 51 and $\geq 52$ years (Table 3 ). Younger men ( $\leq 29$ years) had lower HÖ-MEQ score than older men ( $\geq 52$ years). However, there were no differences between genders regardless of age, or overall averages for men and women $\left(\sigma^{\star}=57.7 \pm 8.8 ;\right.$; $\left.=59.5 \pm 10.3 ; p=0.094\right)$.

Despite the chronotype categorization into three categories, the data referring to the evening data were excluded from logistic regression due to the low number of individuals in this group. Age, female gender and preference for exercise during the day are associated with the morning chronotype (Table 4). The probability of belonging to the morning group increases by $4 \%$ for each year of life compared to the neither group $(p=0.023$; Odds ratio $=$ $\left.1.041 ; \mathrm{CI}_{95 \%}=1.005-1.078\right)$.

Moreover, specifically being female increases the probability of belonging to the morning group by $174 \%$ compared to the male gender $(p=0.005$; Odds ratio $=$
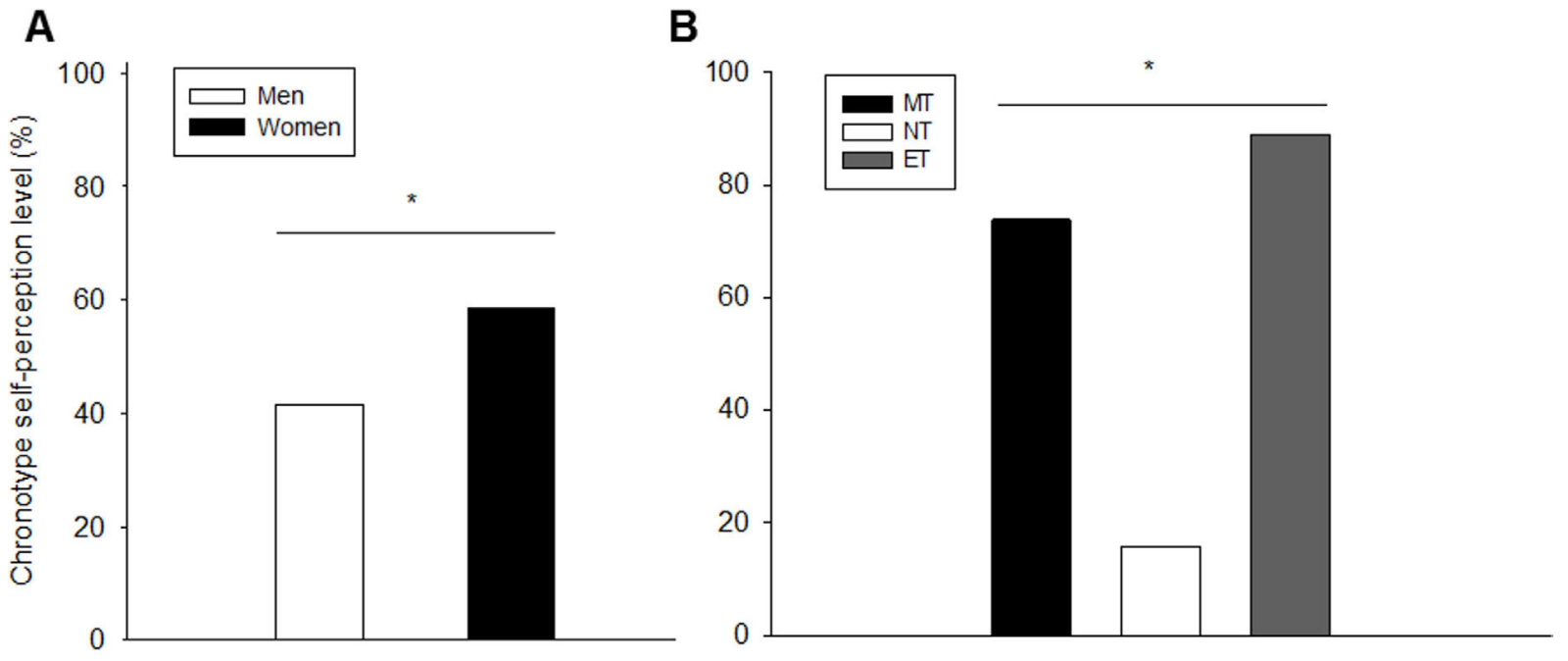

Figure 2. - Chronotype self-perception level (\%) by gender (A) and chronotypes (B). MT (morning-types), NT (neither-types), ET (evening-types). *denote difference from MT and NT to expected values $(p<0.05)$. 
Table 3 - Stratification of HÖ-MEQ scores by gender and age range.

\begin{tabular}{|c|c|c|c|c|}
\hline Age range & Gender & HÖ-MEQ & $n$ & $p$ \\
\hline \multirow[t]{2}{*}{$\leq 29$ years } & 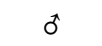 & $54.4 \pm 9.3$ & 12 & 0.050 \\
\hline & q & $55.1 \pm 8.9$ & 16 & n.s \\
\hline \multirow[t]{2}{*}{$30-40$ years } & $0^{2}$ & $56.1 \pm 7.9$ & 34 & n.s \\
\hline & o & $59.7 \pm 10.4$ & 43 & $\mathrm{n} . \mathrm{s}$ \\
\hline \multirow[t]{2}{*}{$41-51$ years } & $0^{2}$ & $59.3 \pm 9.0$ & 19 & n.s \\
\hline & q & $61.7 \pm 10.7$ & 22 & $\mathrm{n} . \mathrm{s}$ \\
\hline \multirow[t]{2}{*}{$\geq 52$ years } & $\sigma^{0}$ & $63.1 \pm 8.7$ & 12 & $\mathrm{n} . \mathrm{s}$ \\
\hline & q & $61.4 \pm 9.6$ & 8 & $\mathrm{n} . \mathrm{s}$ \\
\hline
\end{tabular}

Legend: Data presented as mean \pm standard deviation.

*denote difference from men $\leq 29 v s . \geq 52$ years; $n . s=$ not significant

2.742; $\mathrm{CI}_{95 \%}=1.347-5.581$ ). In addition, preferring to perform physical exercises during the day increases the probability of belonging to the morning group by $213 \%$ compared to the group at no specific time $(p=0.037$; Odds ratio $\left.=3.133 ; \mathrm{Cl}_{95 \%}=1.070-9.173\right)$, and increases the probability by $464 \%$ compared to the evening group $\left(p<0.001\right.$; Odds ratio $\left.=5.640 ; \mathrm{CI}_{95 \%}=2.363-13.458\right)$.

\section{Discussion}

The aims of the present study were to verify the selfperception level of the chronotype of amateur street runners and to test the association between the chronotype and the gender, age and preferred training time. The main finding was that the self-perception level of the chronotype was higher in women compared to men. Nonetheless, the difference in the chronotype distribution frequency between the two genders demonstrated a gender effect. In practice, these results could be a key point for consideration by trainers and physical educators when scheduling training sessions or choosing a competition, mainly based on a possible effect of chronotype on athletic performance.

It is necessary to highlight that the hypothesis that there would be a relationship between gender and chronotype has been investigated with representative samples, especially with an interaction of the age factor. In our study, younger men had lower HÖ-MEQ scores than their older peers ( $\leq 29$ vs. $\geq 52$ years), indicating an ontogenic dynamic of chronotype variation. The presence of this phenomenon was reported by Fischer et al. ${ }^{18}$ indicating that the eveningness peak in men and women occurs around 19 and 20 years old, respectively, and that men tend to be more MT than women after 40 years old. Accordingly, Duarte et al. ${ }^{19}$ also showed a phase delay in adolescents and a phase advance in Brazilians older adults, and this seems to be a phenomenon which is markedly more present in men. It is speculated that the most likely reason for this variability in chronotype of men and women appears to be related to hormonal factors ${ }^{18,19}$. Testosterone is known to play an important role in chronotype changes during puberty in mammals ${ }^{23}$. In humans, some evidence suggests the presence of sex hormone receptors in the suprachiasmatic nucleus of the hypothalamus ${ }^{24}$. Moreover, it is important to mention about the changes that occur in sleep phase preferences during puberty, especially in the 5 years post-menarche. At older ages, we can summarize that decreased testosterone and estrogen during menopause (female) and andropause (male) could explain a trend towards morningness in this age range ${ }^{19}$. Chronically, it is believed that the increased incidence of morningness habits with advancing age may cause changes in the chronobiological phenotype, in particular due to changes in the sensitivity of the endogenous timing system to the light-dark cycle, regardless of gender ${ }^{25}$.

In other study involving hormonal circadian regulation, Gunn et al. ${ }^{26}$ observed that females exhibited significantly greater levels of plasma melatonin and cortisol than males. Females also exhibited a significantly higher amplitude rhythm in both hormones. However, the authors reported that was not possible to distinguish whether the elevated plasma melatonin and cortisol levels observed in females resulted from innate sex differences or the oral contraceptive pill affecting the synthetic and metabolic pathways of these hormones. Conversely, non-hormonal causes can act as modulators of the circadian timing sys-

Table 4 - Model Coefficients - Chronotypes.

\begin{tabular}{|c|c|c|c|c|c|c|c|}
\hline \multirow[b]{2}{*}{ Predictor } & \multirow[b]{2}{*}{ Estimate } & \multirow[b]{2}{*}{ SE } & \multirow[b]{2}{*}{$\mathbf{Z}$} & \multirow[b]{2}{*}{$p$} & \multirow[b]{2}{*}{ Odds ratio } & \multicolumn{2}{|c|}{ 95\% Confidence Interval } \\
\hline & & & & & & Lower & Upper \\
\hline Intercept & -1.2686 & 0.731 & -1.73 & 0.083 & 0.281 & 0.067 & 1.179 \\
\hline Age & 0.040 & 0.017 & 2.27 & 0.023 & 1.041 & 1.005 & 1.078 \\
\hline \multicolumn{8}{|l|}{ Gender: } \\
\hline female - male & 1.008 & 0.362 & 2.78 & 0.005 & 2.742 & 1.347 & 5.581 \\
\hline \multicolumn{8}{|l|}{ Schedule: } \\
\hline Day - Night & 1.729 & 0.443 & 3.90 & $<0.001$ & 5.640 & 2.363 & 13.458 \\
\hline Day - Any time & 1.142 & 0.548 & 2.08 & 0.037 & 3.133 & 1.070 & 9.173 \\
\hline
\end{tabular}

Legend: Estimates represent the log odds of MT vs. NT. Collinearity Statistics (Tolerance): Age $=0.988 ;$ Gender $=0.982 ;$ Schedule $=0.991 . \%$ Correct: $\mathrm{NT}=56.5 \% ; \mathrm{MT}=78.4$. Accuracy $=0.688$. 
tem, as well as behavioral and social factors (i.e. family lifestyle and work regimes), in addition to somatic and mental disordes ${ }^{18,19}$.

There was a general predominance of MT among runners $(n=88 ; 53 \%)$, which can be partially explained by the predominance of this phenotype among women. According to Henst et al. ${ }^{7}$ the predominance of morningness in South African marathon runners compared to Dutch athletes seems to be related to climatic issues, since the prevailing climate in Africa predisposes individuals to perform training in the morning, in addition to the fact that the competitions almost always occur in the morning. Thus, the summing effects of the climate, training schedule and higher training volume throughout the week for South Africans predispose individuals to the morning profile. In fact, the typical climatic conditions of tropical countries like Brazil and South Africa can partially explain these results. However, our sample group consisted of amateur runners, with little control over physical training parameters and who train and/or compete at different times of the day.

When asked about the preferred training time, runners classified as MT and ET reported preferring to train in the morning (73.9\%) and evening (88.9\%), respectively. Conversely, only $15.9 \%$ of NT individuals corroborated the theoretical hypothesis assumed for this category of not having any specific preferred time, thus reflecting the absence of an individual pattern for this group. Our results also demonstrated that the preference for physical exercise in the morning increases the probability of belonging to the morning group by $213 \%$ compared to the no specific time group, and increases the probability by $464 \%$ when compared to the evening group. It should be noted that the preference may not reflect the actual training and competitions schedule ${ }^{11}$, although individually these athletes have better flexibility regarding their training schedule compared to collective characteristic modalities ${ }^{9}$. Cruz et al. ${ }^{8}$ pointed out that the overload of daily, work and family activities means that many amateur morning runners are unable to reconcile their training schedules with their individual preferences. In fact, these studies demonstrate the importance of adapting the practice schedule according to the chronotype, especially according to the chronotype obtained through the HÖ-MEQ. Kunorozva et al. ${ }^{10}$ observed that the subjective perception of effort by cyclists who were proven to be submitted to tests with varying intensities at different times is higher during the evening (18 and $22 \mathrm{~h}$ ) when compared to other periods (6, $10,14 \mathrm{~h}$ ), indicating greater capacity to resist fatigue in the early hours of the day.

Another important point for discussion concerns the way of interpreting and classifying the data obtained in the HÖ-MEQ. According to the original reference proposed by Horne \& Östberg ${ }^{3}$, the chronotype is classified into five subtypes, being MT and ET divided into moderates and extremes, in addition to neither-types. In this perspective, the NT would be prevalent in the present study $(n=69)$ and no longer the MT as effectively observed, as we would have 24 extreme morning-types and 64 moderate morning-types. In fact, this is not an error, but an important aspect to consider for analyzing and interpreting the results. In this scenario, athletes would behave similarly to the majority of the non-athlete adult population ${ }^{21}$. However, several studies have adopted the classification model grouped into only three categories, without subdividing morning-types and evening-types ${ }^{2,8,10-12,27}$. Although not justified, it is assumed that this model was chosen because the extreme individuals are not so present and/or to facilitate statistical analysis of the data.

\section{Conclusion}

Women runners showed a greater perception of their circadian traits than men, despite there was no association between gender and preferred training time. Further studies should be designed to assess the chronotype relationship with gender and age over time in different sports, and if possible, including hormonal analysis and performance parameters.

\section{Acknowledgments}

The authors would like to thank the National Council for Scientific and Technological Development $(C N P q)$, the Dean of Research and Graduate Studies (PROPPG/ $U E M G$ ), the Coordination for the Improvement of Higher Education Personnel (CAPES), the Dean of Research of the Federal University of Minas Gerais ( $P R P Q / U F M G)$ with a grant for F.S.M.M. (CAPES/Print, no. 88887.364935/2019-00), and the Minas Gerais Research Support Foundation $(F A P E M I G)$ for the financial support granted through the call for tenders BIP/2017 (00262-17).

\section{References}

1. Brazilian Athletics Confederation. Recognition and approval of street races and ultra-marathons. CBAt Web site. Available from: https://www.cbat.org.br. [Acessed 13th November 2018].

2. Vitale JA, Bjoerkesett E, Campana A, Panizza G, Weydahl A. Chronotype and response to training during the polar night: a pilot study. Int J Circumpolar Health. 2017;76 (1):1320919.

3. Horne JA, Östberg O. A self-assessment questionnaire to determine morningness-eveningness in human circadian rhythms. Int J Chronobiol. 1976; 4(2):97-110.

4. Smith CS, Reilly C, Midkiff K. Evaluation of three circadian rhythm questionnaires with suggestions for an improved measure of morningness. J Appl Psychol. 1989;74 (5):728-38. 
5. Roenneberg T, Wirz-Justice A, Merrow M. Life between clocks: daily temporal patterns of human chronotypes. J Biol Rhythms. 2003;18(1):80-90.

6. Roenneberg T. Having Trouble Typing? What on Earth Is Chronotype? J Biol Rhythms. 2015; 30(6):487-91.

7. Henst RH, Jaspers RT, Roden LC, Rae DE. A chronotype comparison of South African and Dutch marathon runners: The role of scheduled race start times and effects on performance. Chronobiol Int. 2015;32(6):858-68.

8. Cruz I, Franco B, Esteves AM. Qualidade do sono, cronotipo e desempenho em corredores de rua. Rev Bras Med Esporte. 2017;23(6):483-7.

9. Kunorozva L, Rae DE, Roden LC. Chronotype distribution in professional rugby players: Evidence for the environment hypothesis? Chronobiol Int. 2017;34(6):762-72.

10. Kunorozva L, Roden LC, Rae DE. Perception of effort in morning-type cyclists is lower when exercising in the morning. J Sports Sci. 2014;32(10):917-25.

11. Rae DE, Stephenson KJ, Roden LC. Factors to consider when assessing diurnal variations in sports performance: the influence of chronotypes and habitual training time-of-day. Eur J Appl Physiol. 2015;115(6):1339-49.

12. Brown FM, Neft EE, LaJambe CM. Collegiate rowing crew performance varies by morningness-eveningness. J Strength Cond Res. 2008;22(6):1894-900.

13. Facer-Childs E, Brandstaetter R. Circadian phenotype composition is a major predictor of diurnal physical performance in teams. Front Neurol. 2015;6:208.

14. Facer-Childs E, Brandstaetter R. The impact of circadian phenotype and time since awakening on diurnal performance in athletes. Curr Biol. 2015;25(4):518-22.

15. Mohawk JA, Green CB, Takahashi JS. Central and peripheral circadian clocks in mammals. Annu Rev Neurosci. 2012;35:445-62.

16. Minati A, de Santana MG, de Mello MT. A influência dos ritmos circadianos no desempenho físico. $\mathrm{R}$ Bras $\mathrm{Ci}$ e Mov. 2006;14(1):75-86.

17. Randler C, Vollmer C. Epidemiological evidence for the bimodal chronotype using the composite scale of morningness. Chronobiol Int. 2012;29(1):1-4.

18. Fischer D, Lombardi DA, Marucci-Wellman H, Roenneberg T. Chronotypes in the US - Influence of age and sex. PLoS ONE. 2017;12(6): e0178782.

19. Duarte LL, Menna-Barreto L, Miguel MAL, Louzada F, Araújo J, Alam M, et al. Chronotype ontogeny related to gender. Braz J Med Biol Res. 2014;47(4): 316-20.
20. Benedito-Silva AA, Menna-Barreto L, Marques N, Tenreiro S. A self-assessment questionnaire for the determination of morningness-eveningness types in Brazil. Prog Clin Biol Res. 1990; 341B: 89-98.

21. Roden LC, Rudner T, Rae D. Impact of chronotype on athletic performance: current perspectives. Chronophysiol Ther. 2017;7:1-6.

22. Vitale JA, Weydahl, A. Chronotype, physical activity, and sport performance: a systematic review - Sports Med. 2017; Sep; 47(9):1859-68.

23. Hagenauer MH, Ku JH, Lee TM. Chronotype changes during puberty depend on gonadal hormones in the slow-developing rodent. Octodon degus. Horm Behav. 2011; 60:37-45.

24. Kruijver FP, Swaab DF. Sex hormone receptors are present in the human suprachiasmatic nucleus. Neuroendocrinology. 2002; 75:296-305.

25. Von Schantz M, Taporoski TP, Horimoto ARVR, Duarte NE, Vallada H, Krieger JE, et al. Distribution and heritability of diurnal preference (chronotype) in a rural Brazilian family-based cohort, the Baependi study. Sci Rep. 2015;5:9214.

26. Gunn PJ, Middleton B, Davies SK, Revell VL, Skene DJ. Sex differences in the circadian profiles of melatonin and cortisol in plasma and urine matrices under constant routine conditions. Chronobiol Int. 2016;33(1):39-50.

27. Rossi A, Formenti D, Vitale JA, Calogiuri G, Weydahl A. The effect of chronotype on psychophysiological responses during aerobic self-paced exercises. Percept Mot Skills. 2015;121(3):840-55.

\section{Corresponding author}

Moisés Vieira de Carvalho. Universidade do Estado de Minas Gerais, Departamento de Ciências do Movimento Humano, Av.São Paulo, 3996, 32400-000, Ibirité, MG, Brasil.

E-mail: moises.carvalho@uemg.br.

Manuscript received on May 31, 2021

Manuscript accepted on June 6, 2021

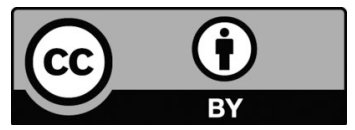

Motriz. The Journal of Physical Education. UNESP. Rio Claro, SP, Brazil - eISSN: 1980-6574 - under a license Creative Commons - Version 4.0 